\title{
EFFECT OF ETHYL METHANE SULFONATE (EMS) ON INCUBATION PERIOD, PUPAL PERIOD AND REPRODUCTIVE POTENTIAL OF LADYBIRD BEETLE, EPILACHNA VIGINTIOCTOPUNCTATA FAB
}

\author{
A.E. Ekram, I. Sarker, M.P.E. Shaekh, R. Khatun and K. M. F. Hoque* \\ Department of Genetic Engineering and Biotechnology, University of Rajshahi, Rajshahi-6205 \\ *Corresponding author's e-mail: kmfhoque03_gen@yahoo.com
}

Keywords: EMS, incubation, pupal period, reproductive potential and ladybird beetle.

Ladybird beetle, Epilachna vigintioctopunctata Fab. is a serious pest of brinjal (Solanum melongena), potato and other solanaceous plants (Jotwani et al. 1963; Azam et al. 1974). It belongs to the family Coccinellidae and order Coleoptera, both the adult and larvae cause damage by feeding on the upper surface of leaves. Adults and larvae feed on leaves by scraping away the surface cells between the main veins to leave irregular-shaped holes or strips giving them a skeletonized or lace-like appearance when infestation is severe. Damaged leaves turn brown, curl up and die before falling off (Atwal 1976). It was described by Rehman (1940) that larvae of E. vigintioctopunctata (F.) confined their attack on the lower surface of the brinjal leaves whereas the adults feed on the upper surface.

Many alkylating agents have been found to exert a mutagenic effect on a great variety of organisms but very little evidences have been established with experiments in E. vigintioctopunctata Fab. as the test system. These chemical agents vary in their composition and structure from simple to very complex molecules which can be classified in two main groups, the mono and poly functional agents. According to Aslaniyan and Smirnova (1981), ethyl methane sulfonate (EMS) is a monofunctional alkylating agent which is treated as a super mutagen.

In the study of chemical mutagenesis in biological systems, it is important to establish accurate dosimetric techniques relating the administered doses of chemical agent to the number of potentially mutagenic events occurring in individual cells (Sega et al. 1974). The relationship between dosage and mutational response has been used extensively in radiation genetics for distinguishing between different mechanisms of mutation induction and for establishing a basis for estimating risk at low dosage for results at moderate to higher dosage. Unfortunately, as a quantitative science the field of chemical mutagenesis has not progressed as rapidly as did radiation genetics.
It is particularly urgent to better understand the action of above chemical compounds, their dose effects, their combined effects etc. This will allow a better assessment of benefit versus risk. Moreover, an important lesson to be learned from a study of this kind is that fundamental research on the mechanisms of how a particular chemical structure produces mutations can be of great practical interest (Sobels 1982). In Bangladesh, no significant attempt has been made to study the effect of ethyl methane sulfonate on the biology of E. vigintioctopunctata Fab. So, attempts were made to know the effect of EMS on the incubation period, pupal period, reproductive potential and hatchability of Epilachna vigintioctopunctata Fab.

The study was conducted in the Insect Genetics Laboratory, Department of Genetic Engineering and Biotechnology, University of Rajshahi. Ladybird beetle, Epilachna vigintioctopunctata and 1.0, 0.75 and 0.5 percent of Ethyl methane sulfonate (EMS) were used in this experiment.

Collection and Culture of Beetles: Adult beetles, larvae and pupae were collected from "Baharompur" (village) at Rajshahi and the field of Rajshahi University Campus to make a stock culture, maintained in the Insect Genetics Laboratory for continuous supply of the test insects. Adult beetles collected from the field, reared in the laboratory at normal room temperature. To maintain stock culture in transparent plastic cage, $(80 \times 90 \mathrm{~cm})$ supplied with fresh middle aged leaves of Solanum indicum. A piece of wet synthetic sponge was kept at the bottom of the cage to keep the leaves fresh. Fifteen to twenty adults were kept in a cage and the mouth of the cage was covered by a piece of fine muslin cloth tied with a rubber band. These cultures were observed regularly and only healthy cultures were kept. Dead individuals were removed and leaves were replaced time-to-time by new ones. Newly hatched larvae were collected with camel hair brush and transferred to a fresh food medium. 
Collection of $3^{\text {rd }}$ Instar Larvae and Application of EMS: The larval instars were determined by counting the exuviae (larval skin) deposited in the food medium or plastic cage. Four larval instars were observed in the study. At room temperature $1^{\text {st }}$ instar larvae were observed after 3 to 4 days of egg laying. The $2^{\text {nd }}, 3^{\text {rd }}$ and $4^{\text {th }}$ larval instars each took 3-4 days to moult to next instar. The expected $3^{\text {rd }}$ instar larvae of $E$. vigintioctopunctata Fab. were treated by the different concentrations $0.5,0.75$ and $1.0 \%$ of EMS. Each solution of EMS was taken into beakers and some leaves were drenched into the each solution for 5 minutes. Then the leaves were then placed in different plastic cages and 10 larvae of the beetle were released in each cage. The experiment was conducted with Completely Randomized Design (CRD) with five replications for each dose and continued for three successive generations.

Collection of Pupae and Adults: After pupation pupae were collected and kept in a separate plastic cage to get adults. Five pairs of newly emerged beetles of the same age were allowed to mate in five different plastic cages. The egg laying habits was observed and the number of egg was counted. The number of newly hatched larvae was counted for recording (\%) hatching. The newly hatched larvae were transferred to another plastic cage $(90 \mathrm{~cm} \times 80 \mathrm{~cm})$ and reared separately. The larval stages were checked regularly and the time of each molting was recorded in each stage. During the rearing, pupal period was also recorded. The number of adults emerged from the pupae and also the unemerged pupae counted. The percentage of emergence was thus calculated. After emergence, the imago were sexed and reared separately to maintain a stock culture. A pair of newly emerged beetles was transferred to the plastic cages and fresh leaves were supplied regularly. Whenever the male or female beetle happened to die, another male or female to fulfill the experimental conditions replaced it. The method applied in this experiment was in accordance with Ahmed (1983).

The average incubation periods of $E$. vigintioctopunctata were $4.23 \pm 0.06,4.50 \pm 0.07,4.61 \pm 0.11,4.07 \pm 0.06$ days in the $1^{\text {st }}$ generation, $4.12 \pm 0.07,4.23 \pm 0.07,4.32 \pm 0.09$, $3.94 \pm 0.07$ days in the $2^{\text {nd }}$ generation and $4.09 \pm 0.06$, $4.15 \pm 0.06, \quad 4.27 \pm 0.06, \quad 4.00 \pm 0.07$ days in the $3^{\text {rd }}$ generation for $0.5,0.75$ and $1.0 \%$ of EMS and for control doses respectively. EMS significantly prolonged, $\left(\mathbf{F}_{3(11)}=4.66 ; \mathbf{P}<0.036\right)$ on the incubation period of $E$. vigintioctopunctata in all generations(Table 1). Information regarding the effect of EMS on the incubation period of E. vigintioctopunctata is not available and as such no comparison can be made.
However, it was in good agreement with the previous findings of Ahmed et al. (1976), who reported that gamma irradiation at higher doses (i.e. 1000r, 2000r and 3000r) prolonged the incubation period of Sitotroga cerealella oliv.

The average pupal periods were $4.77 \pm 0.16,5.08 \pm 0.16$, $5.11 \pm 0.16,4.48 \pm 0.17$ days in the $1^{\text {st }}$ generation, $4.68 \pm 0.16,4.95 \pm 0.18,5.03 \pm 0.17,4.41 \pm 0.16$ days in the $2^{\text {nd }}$ generation and $4.63 \pm 0.16,4.84 \pm 0.19,4.94 \pm 0.20$, $4.29 \pm 0.16$ days in the $3^{\text {rd }}$ generation for $0.5,0.75$ and $1.0 \%$ of EMS and control respectively. The pupal period was significantly $\left(\mathbf{F}_{3(11)} \quad=\mathbf{2 7 . 6 6 ;} \mathbf{P}<\mathbf{0 . 0 0 1}\right)$ prolonged in comparison of the control (Table 1). Information regarding the effect of EMS on the pupal period of E. vigintioctopunctata Fab. is not available and a comparative study for the effect of EMS on both incubation and pupal period (Fig. 1).was done.

The treatment of EMS showed significant $\left(\mathbf{F}_{3(11)}\right.$ $=46.06 ; \mathbf{P}<0.00002)$ effect on reproductive potential of $E$. vigintioctopunctata (Table 2). The average numbers of eggs laid by female beetles were $708.60 \pm 87.28$, $691.00 \pm 85.83,675.40 \pm 87.45,750.00 \pm 84.53$ in the $1^{\text {st }}$ generation. 710.00 $\pm 87.66,692.00 \pm 87.56,677.20 \pm 88.10$, $733.40 \pm 78.57$ in the $2^{\text {nd }}$ generation and $723.00 \pm 85.71$, $703.60 \pm 87.06,682.00 \pm 89.60,742.00 \pm 88.38$ in the $3^{\text {rd }}$ generation for $0.5,0.75$ and $1.0 \%$ of EMS and for control respectively. The reproductive potential of $E$. vigintioctopunctata was highly sensitive to the higher dose of EMS and lower dose is ineffective and produced no significant change (Fig. 2). It was in good agreement with the previous findings of Tazima (1964) who reported that there was no appreciable change in the fecundity of silkworm even after treatment with $3000 \mathrm{r}$ at pupal stages.

The average percentages of egg-hatch were $87.92 \pm 1.12$, $79.33 \pm 2.14, \quad 77.80 \pm 3.03, \quad 91.06 \pm 1.17$ in the $1^{\text {st }}$ generation, $90.20 \pm 1.71, \quad 80.69 \pm 4.19, \quad 76.93 \pm 1.78$, $92.97 \pm 1.03$ in the $2^{\text {nd }}$ generation and $89.23 \pm 1.76$, $85.36 \pm 2.34, \quad 80.29 \pm 1.44, \quad 93.82 \pm 0.99$ in the $3^{\text {rd }}$ generation for 0.5.0.75 and 1.0\% of EMS and control respectively. The effect $\left(\mathbf{F}_{\mathbf{3}(11)}=\mathbf{3 1 . 4 9} ; \mathbf{p}<\mathbf{0 . 0 0 0 1}\right)$ was also very significant on hatching of Ladybird beetle (Table 2). The findings are in good agreement with the previous findings of Ikebuchi and Nakao (1979) where they observed that percentage of hatchability decreased markedly at higher doses. Similar results are also found by Cowrin (1968), Lee (1978) and Ryo (1981) they used N-nitrosomethylurea, ethyl methane sulfonate respectively in Drosophila melanogaster. These results also conform to those of Pai et al. (1985) who have shown that the decreased percentage of hatchability was 
directly dependent on the concentrations used. Datta (1978) observed that the larvae and pupae of B. mori L. were injected with $0.05,0.1$ and $0.15 \%$ solutions of EMS caused reduction in the number of spermatozoa, which ultimately decreased the hatchability. Larvae and pupae of Bombyx females were injected with EMS by Murakami (1975), using the specific locus mutants pe and re. Dominant lethal mutation induced in late pupal prophase-I oocytes but not in larval growth stage

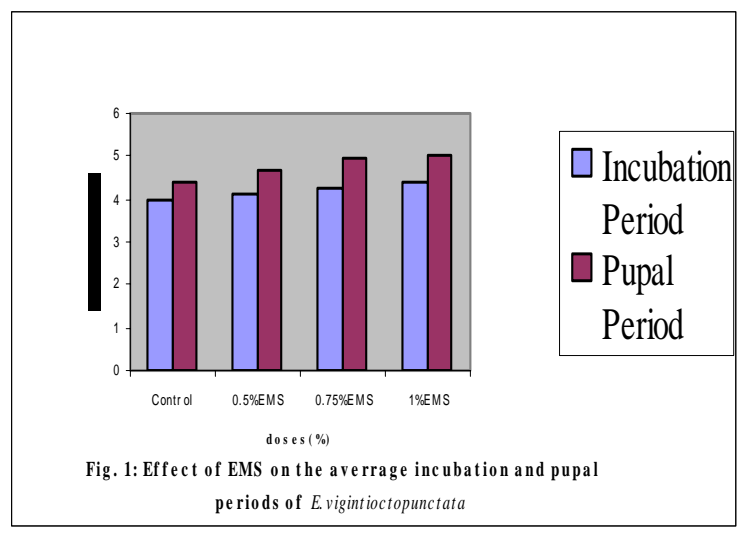

oocytes. As a result this ultimately decreased the hatchability.

The finding shows that EMS has an external effect on incubation period, pupal period, reproductive potential and hatchability of ladybird beetle. EMS changed the structure of ladybird beetle and this change is continued from generation after generation. So this change is genetical, not environmental.

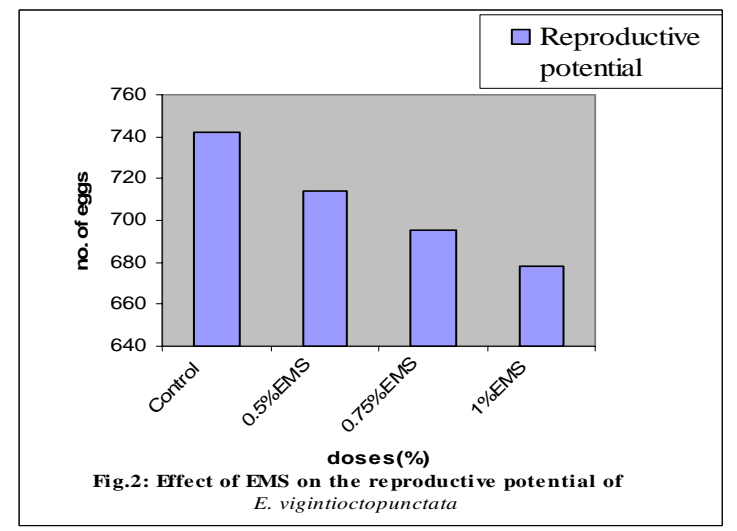

Table 1 Effect of ethyl methane sulfonate (EMS) on the incubation and pupal periods of E. vigintioctopunctata.

\begin{tabular}{|c|c|c|c|c|c|c|}
\hline \multirow{3}{*}{ Doses (ml) } & \multicolumn{3}{|c|}{ Incubation period } & \multirow{2}{*}{\multicolumn{3}{|c|}{$\begin{array}{c}\text { Pupal period } \\
\text { No. of generations (days) }\end{array}$}} \\
\hline & \multicolumn{3}{|c|}{ No. of generations (days) } & & & \\
\hline & 1 & 2 & 3 & \multirow{2}{*}{$\begin{array}{c}1 \\
4.77\end{array}$} & \multirow{2}{*}{$\begin{array}{l}\text { neratic } \\
4.68\end{array}$} & \multirow{2}{*}{$\begin{array}{c}3 \\
4.63\end{array}$} \\
\hline 0.50 & 4.23 & 4.12 & 4.09 & & & \\
\hline 0.75 & 4.50 & 4.23 & 4.15 & 5.08 & 4.95 & 4.84 \\
\hline 1.00 & 4.61 & 4.32 & 4.27 & 5.11 & 5.03 & 4.94 \\
\hline Control & 4.07 & 3.94 & 4.00 & 4.48 & 4.41 & 4.29 \\
\hline $\begin{array}{c}\text { C.F., } \\
\text { Total sum of squares } \\
\text { (T.SS), Sum of squares } \\
\text { between doses (SS). }\end{array}$ & Sum & $\begin{array}{c}\text { Total sum of squares }(\mathrm{T} . \mathrm{SS})=0.423 \\
\text { Sum of squares between doses }(\mathrm{SS})=0.269\end{array}$ & .269 & \multirow{2}{*}{\multicolumn{3}{|c|}{$\begin{array}{c}\text { Total sum of squares }(\mathrm{T} . \mathrm{SS})=0.817 \\
\text { Sum of squares between doses }(\mathrm{SS})=0.745 \\
\mathbf{2 7 . 6 5 7}(\mathbf{p}<\mathbf{0 . 0 0 1})\end{array}$}} \\
\hline Variance ratio(F) & \multicolumn{3}{|c|}{$4.66(p<0.036)$} & & & \\
\hline
\end{tabular}

Table 2 Effect of ethyl methane sulfonate (EMS) on the reproductive potential and hatching ability of E. vigintioctopunctata.

\begin{tabular}{|c|c|c|c|c|c|c|}
\hline \multirow{3}{*}{ Doses (ml) } & \multicolumn{3}{|c|}{ Reproductive potential } & \multirow{2}{*}{\multicolumn{3}{|c|}{$\begin{array}{l}\text { Hatching period } \\
\text { tions (\% of egg hatched) }\end{array}$}} \\
\hline & \multicolumn{3}{|c|}{ No. of generations (eggs) } & & & \\
\hline & 1 & 2 & 3 & \multirow{5}{*}{$\begin{array}{c}1 \\
87.92 \\
79.33 \\
77.80 \\
91.06\end{array}$} & \multirow{2}{*}{$\begin{array}{c}2 \\
90.20\end{array}$} & \multirow{2}{*}{$\begin{array}{c}3 \\
89.23\end{array}$} \\
\hline 0.50 & 708.6 & 710.0 & 723.0 & & & \\
\hline 0.75 & 691.0 & 692.0 & 703.6 & & 80.69 & 85.36 \\
\hline 1.00 & 675.4 & 677.2 & 682.0 & & 76.93 & 80.29 \\
\hline Control & 750.0 & 733.4 & 742.0 & & 92.97 & 93.82 \\
\hline $\begin{array}{c}\text { C.F., } \\
\text { Total sum of squares } \\
\text { (T.SS), Sum of } \\
\text { squares between } \\
\text { doses (SS). }\end{array}$ & \multicolumn{3}{|c|}{$\begin{array}{l}\text { C.F. }=\frac{\mathrm{GT}^{2}}{\mathrm{~N}}=6004128.27 \\
\text { sum of squares }(\mathrm{T} . \mathrm{SS})=7041.210 \\
\text { quares between doses }(\mathrm{SS})=6656.877\end{array}$} & $\begin{array}{l}\text { Tota } \\
\text { Sum of }\end{array}$ & 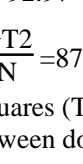 & $\begin{array}{l}8.886 \\
=386.183\end{array}$ \\
\hline Variance ratio(F) & \multicolumn{3}{|c|}{$46.061(p<0.00002)$} & \multicolumn{3}{|c|}{$31.490(p<0.0001)$} \\
\hline
\end{tabular}

Acknowledgement: The authors would like to thank the Dept. of Genetic Engineering and Biotechnology,
Rajshahi University for providing with lab. facilities to carry out this research work. 


\section{References}

Ahmed A 1983. Bionomics, Ecology and control of Epilachna beetles of Rajshahi University campus and adjacent areas. M. Phil. Thesis. Dept. of Zool. Rajshahi Univ. 124 pp.

Ahmed MI, Begum A and Khan SA 1976. Radiation effects on mated females of Angoumeis grain moth. Bangladesh J. Zool. 4(1): 55-57.

Anon 1980. Low dose radiosensitivity of the blowfly, Calliphera erytro cephala Meigen (Diptera: Calliphoridae). M.Sc. Thesis. Dept. of Zool. Univ. of Dacca. 52 pp.

Aslaniyan MM and Smirnova VA 1981. Analysis of mutations by alkylating agents in Drosophila spermatozoa, II. The nature of chemically induced unstable mutation in Drosophila melanogaster. Genetika. 17: 684-693.

Atwal AS 1976. Agricultural pests of India and South East Asia. Punjab Agricultural Univ. India. 529 pp.

Azam KM, Aziz SA and Ali MH 1974. A new record of Uga menoni Kerrien as parasite of Epilachna vigintioctopunctata (F.) in India. Current Science. 3(8): 88.

Cowrin HO 1968. The mutagenic effect of N-nitrosomethylurea on the dumpy locus in Drosophila melanogaster. Mutation Res. 5(2): 259-270.

Datta RK, Sengupta K and Das SK 1978. Induction of dominant lethals with ethyl methane sulfonate in male germ cells of mulberry silkworm, Bombyx mori L. Mutation Res. 56: 299-304.

Ikebuchi M and Nakao Y 1979. Storage effects of translocations and dominant lethals induced by ethyl methane sulfonate (EMS) in Drosophila melanogaster. Japan J. Genet. 54: 133-137.
Jotwani Sarup and Pradhan 1963. Comparative toxicity of insecticides to the grubs and adults of Epilachna vigintioctopunctata F. (Coccinellidae: Coleoptera). Indian J. Ent. 24(4): 223-228

Lee WR 1978. Dosimetry of chemical mutagens in eukaryote germ cells. in: A. Hollaender and F. J. de serres (Eds). Chemical mutagenesis. 5: 177-202.

Murakami A 1975. Mutagenic action of ethyl methane sulfonate in oogenesis of the silkworm, Bombyx mori L. Japan J. Genet. 50: 179-187.

Pai IK, Hegde SN and Krishnamurthy NB 1985. Dominant lethals induced by Apron 35 SD in silkworm, Bombyx mori L. Sericologia. 25(3): 343-345.

Rehman 1940. Studies on the biology of Epilachna dodecastigma mutant (= 12 Punctata Mutant) and E. vigintioctopunctata Fab. (=28 Punctata Fab.) Coleoptera: Coccinellidae and selection of their conditions. M. Sc (Ag) Thesis .BAU. 58 pp.

Ryo H, Ito K and Kohdo S 1981. Increment kinetics of recessive lethal mutations and dominant lethals in offspring of Drosophila melanogaster on storage of methyl methane sulfonate treated sperm in females. Mutat. Res. 83: 179-190.

Sega GA, Cumming RB and Walton MF 1974. Dosimetry studies on the ethylation of mouse sperm DNA after in vivo exposure to $\left(3^{\mathrm{H}}\right)$ ethyl methane sulfonate. Mutat. Res. 24: 317-333

Sobels FH 1982. Chemical modification towards loss of mutagenic activity as an alternative to problems involved in risk assessment. Mutat. Res. 102: 305-307.

Tazima Y 1964. The genetics of the silkworm. Elek Books Ltd. London.. 253 pp.

Manuscript received on 2 November 2013 and revised on 8 December 2013 